\title{
Self-inserted foreign bodies during COVID-19: two case reports
}

\author{
Adrian CH Fung *, MB, BS, MRCS, Bess SY Tsui, MB, ChB, FRCS, Sammi YS Wong, MB, ChB, FRCS, \\ YH Tam, MB, ChB, FRCS
}

This article was published on $7 \mathrm{Apr}$ 2021 at www.hkmj.org.
Department of Surgery, Princes of Wales Hospital, Hong Kong

* Corresponding author: fungchiheng@gmail.com

Hong Kong Med J 2021;27:142-4

https://doi.org/10.12809/hkmj208858

\section{Case reports}

\section{Patient 1}

In June 2020, a 12-year-old boy presented to the emergency department with a 1-day history of retained electrical wire in the urethra. The electrical wire had been self-inserted into the urethra in an attempt to relieve "urethral itchiness". He reported pain and gross haematuria as a result of this insertion. He and his mother had been unable to remove the wire. Upon admission, physical examination and plain abdominal radiograph revealed a tangle of electrical wire at the penile urethra with $20 \mathrm{~cm}$ of wire protruding externally via the urethral meatus (Fig 1a). Removal of the foreign body with $2 \%$ xylocaine gel was attempted but failed so emergency surgery was arranged. Despite general anaesthesia, the tangled electrical wire could not be removed by applying traction to the external end. Surgical removal through urethrotomy at the midpenile urethra was performed (Fig 1b). The wire was fragmented and retrieved completely, and the penile urethra was reconstructed with urethroplasty (Fig 1c).
Upon further discussion with the patient's mother, she revealed that the patient had been having difficulty settling into school and adapting to everyday life following their recent immigration from Taiwan. With school suspended during the coronavirus disease 2019 (COVID-19) pandemic, the patient was often left alone at home, worsening his emotional health. His mother volunteered that he had no history of insertion of foreign body.

He was assessed by the clinical psychologist who diagnosed limited problem-solving skills and autistic features with a strong interest in using electrical wire. Additional parental support was advised and regular follow-up with the clinical psychologist was arranged. The patient was discharged 2 days after his operation with an indwelling urinary catheter in place for 2 weeks.

\section{Patient 2}

In May 2020, a 15-year-old boy was admitted with a 1-day history of a retained plastic bottle in his rectum. He reported recent onset of constipation and had inserted a plastic shampoo container per rectum

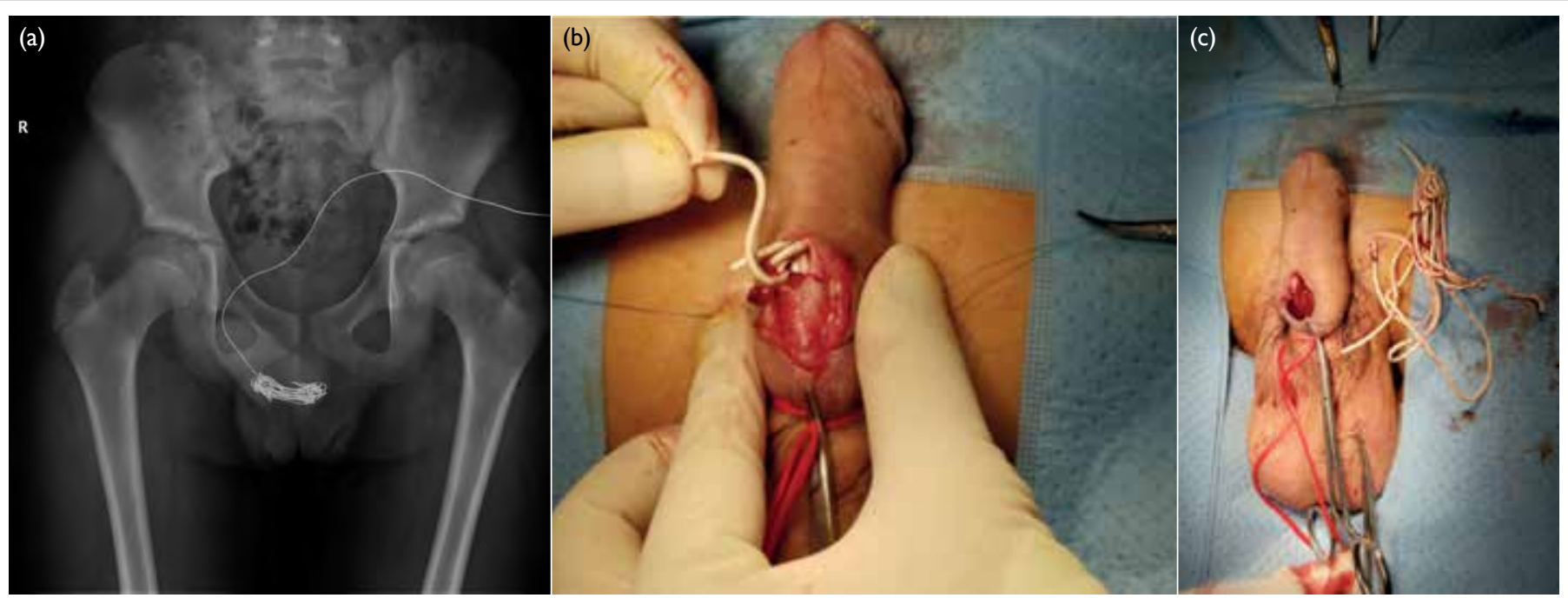

FIG I. (a) A I2-year-old boy presented with a retained electrical wire in the urethra. Radiograph showing a tangle of electrical wire in the penile urethra protruding externally via the tip of the penis. (b) Intra-operative photograph showing retrieval of the tangled electrical wire via urethrotomy. (c) Intra-operative photograph showing the removed electrical wire and urethroplasty in progress 


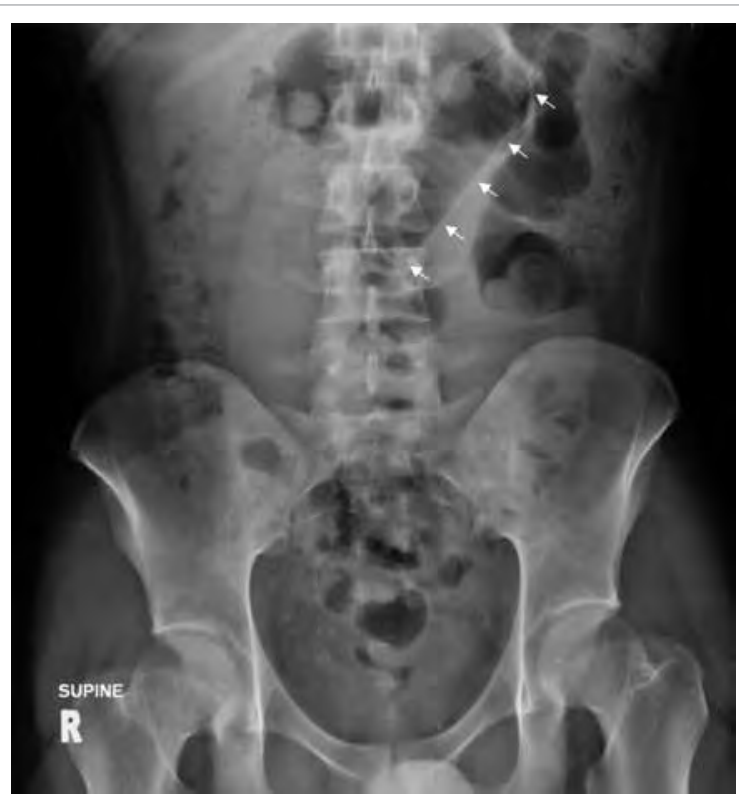

FIG 2. A 15-year-old boy with a retained plastic bottle in the rectum. Radiograph showing the contour of the plastic shampoo bottle (arrows) in the transverse colon region in the hope of inducing a bowel motion. The patient claimed that the idea for this "regimen" was derived from an internet search for a remedy for constipation while school was suspended due to the COVID-19 pandemic. He had no abdominal pain, per rectal bleeding or fever. Physical examination revealed a soft non-distended abdomen. No mass or foreign body was initially felt per rectum. Plain abdominal radiograph revealed the contour of the plastic shampoo bottle in the region of the transverse colon (Fig 2). He was observed overnight in our surgical ward and repeated per rectal examination the next morning found that the plastic bottle was just palpable with a fingertip. The patient subsequently had a bowel motion with passage of the bottle. He was given advice about diet and the correct use of laxatives for constipation prior to discharge on the same day. His parents were interviewed and advised to pay more attention to their son's behaviour at home.

\section{Discussion}

Self-insertion of a foreign body into a body orifice is uncommon in children and adolescents. ${ }^{1}$ Urethral foreign body is even rarer. Motives for teenage intentional foreign body insertion include risktaking, attention-seeking, sexual gratification, selfinjurious behaviour, psychiatric disorder, and selftreatment. ${ }^{2}$ A wide variety of foreign bodies have been reported in the literature, including needles, safety pins, pencils, ball point pens, wire-like objects (telephone cables, feeding tubes, straws, rubber tubing), toothbrushes, household batteries, and nail scissors. ${ }^{1}$ In our patients, electrical wire and a plastic bottle were self-inserted in the urethra and rectum, respectively. Patients with urethral foreign body may present with lower urinary tract symptoms including dysuria, haematuria, urethral discharge, and swelling of the external genitalia. Most patients with self-insertion of a foreign body, because of embarrassment, seek medical attention only after the occurrence of complications such as intestinal obstruction, perforation, genital tract infection, or abscess formation. ${ }^{3}$ Diagnosis can be made in most cases following a comprehensive history taking and physical examination. Radiological evaluation of foreign body with plain radiograph to determine size and number of foreign bodies and their anatomical relationship with surrounding structures usually suffices. Nonetheless ultrasound and computed tomography occasionally may be necessary in selected difficult cases for surgical planning. ${ }^{1,3}$ Endoscopy (eg, cystoscopy or sigmoidoscopy) is considered the first-line option for confirming and removing the foreign body. Open surgery (eg, laparotomy, urethrotomy, or suprapubic cystotomy) has been described for large foreign bodies or when endoscopic removal is deemed impossible. ${ }^{1-3}$ In our first patient, cystoscopic removal was deemed impossible due to tangling of the electrical wire in the penile urethra; therefore, urethrotomy followed by urethroplasty was necessary to fragment and untangle the wire and achieve complete removal. In addition to removal of the foreign body, this group of teenage patients should be advised to obtain proper psychiatric assessment or psychological support as many of them may have mental health issues. ${ }^{1,2}$

The COVID-19 pandemic has impacted the mental well-being of children and adolescents as a result of strict public health measures. In Hong Kong, the Education Bureau ordered classes at all kindergartens and primary and secondary schools to close from February 2019 until midJune. Prevention and Control of Disease Regulation (Cap. 599G) was enforced to restrict the number of persons in group gatherings in public places to maintain social distancing. In mainland China, $>20 \%$ of college students reported mild to severe anxiety as a result of isolation measures and school suspensions in the midst of the pandemic. ${ }^{4}$ Lack of contact with peers, reduced opportunities for stress modulation, increased domestic violence, and child maltreatment have been reported as additional threats to the mental health of children and adolescents. These threats have more impact on those already disadvantaged, such as those with physical disabilities, mental health illness, migrant background, or low socio-economic status. ${ }^{5}$ Our centre observed an increase in foreign body-related 
conditions during this period, with unusual foreign bodies found at unusual sites. Both patients reported herein were emotionally and socially affected by the COVID-19 pandemic. The mental well-being of children and adolescents should be monitored and supported, and these mental health challenges should be addressed with collaboration among the government, schools, parents, and healthcare professionals.

\section{Author contributions}

All authors contributed to the concept or design of the study, acquisition of the data, analysis or interpretation of the data, drafting of the manuscript, and critical revision of the manuscript for important intellectual content. All authors had full access to the data, contributed to the study, approved the final version for publication, and take responsibility for its accuracy and integrity.

\section{Conflicts of interest}

All authors have disclosed no conflicts of interest.

\section{Funding/support}

This case report received no specific grant from any funding agency in the public, commercial, or not-for-profit sectors.

\section{Ethics approval}

The patients were treated in accordance with the tenets of the Declaration of Helsinki. Verbal patient consent was obtained.

\section{References}

1. Prasad Ray R, Ghosh B, Pal DK. Urethral foreign body in an adolescent boy: report of two rare cases and review of literature. Int J Adolesc Med Health 2015;27:463-5.

2. Unruh BT, Nejad SH, Stern TW, Stern TA. Insertion of foreign bodies (polyembolokoilamania): underpinnings and management strategies. Prim Care Companion CNS Disord 2012;14:PCC.11f01192.

3. Ceran C, Uguralp S. Self-inflicted urethrovesical foreign bodies in children. Case Rep Urol 2012;2012:134358.

4. Cao W, Fang Z, Hou G, et al. The psychological impact of the COVID-19 epidemic on college students in China. Psychiatry Res 2020;287:112934.

5. Fegert JM, Vitiello B, Plener PL, Clemens V. Challenges and burden of the Coronavirus 2019 (COVID-19) pandemic for child and adolescent mental health: a narrative review to highlight clinical and research needs in the acute phase and the long return to normality. Child Adolesc Psychiatry Ment Health 2020;14:20. 